\title{
A brief analysis of behaviour possibility of a jointed rock mass near to longwall excavation face simulation using Distinct Elements Method (DEM) in the context of the Beam on Elastic Foundation (BEF) theory
}

\author{
Krzysztof Tomiczek ${ }^{1}$ \\ ${ }^{1}$ Silesian University of Technology, Faculty of Mining and Geology, Department of Geomechanics \\ and Underground Construction, Gliwice, Poland
}

\begin{abstract}
Rock masses are discontinuous medium. Using the program based on the Distinct Element Method (DEM) UDEC (Universal Distinct Element Code) a 2D model of the rock mass near the longwall face was built. The UDEC code, due to its properties, is particularly suitable for modelling discontinuous and jointed rock masses. The coal bed lying at a depth of $700 \mathrm{~m}$ had a thickness of $3 \mathrm{~m}$ and was mined by longwall system with caving. The total face advance was $415 \mathrm{~m}$. The model had dimensions of $1500 \times 500 \mathrm{~m}$ $(w \times h)$. A vertical stress of $\sigma_{z}=7.2 \mathrm{MPa}$ was applied to the upper edge of the model. The mechanized support protected the roof for a length of $4 \mathrm{~m}$ at a distance of $2 \mathrm{~m}$ from the face of the longwall. During simulation, among others, vertical displacements of roof and vertical stresses were closely examined. There were observed phenomena of bending, cracking, loosening and falling of roof blocks of rock. The results of numerical simulations were compared with the results of analytical solutions. The calculations were based on the solutions of the elastic foundation beam theory and the stress wave theory. Comparable shapes of arch pressure $\sigma_{z \max }$ and the range of its impact were obtained.
\end{abstract}

Keywords: Distinct Elements Method, DEM, UDEC, numerical modelling, bend of roof, arch pressure, stress wave theory, bend of the beam on the elastic foundation, cracking of rocks, discontinuities.

\section{Introduction}

Describing the state of stress in the vicinity of mining excavations is a complicated task. "It results mainly from the dimensions of excavations and their range in the analysed rock mass. The variety of rocks and their geomechanical properties in the vicinity of the longwall mining

\footnotetext{
${ }^{1}$ Corresponding author: Krzysztof.Tomiczek@polsl.pl,k.tomiczek@hotmail.com .
} 
make problematic assumptions about homogeneity, isotropy and often also continuity of the analysed rock masses" [1].

In Poland, longwall mining system with caving is commonly used. As Kłeczek writes, the problem of stress distribution in the vicinity of a longwall work is complex. There is no universal theory, which shows full compliance of the results of calculations for various geological and mining conditions with in-situ measurements. Particularly complex is the problem of the roof layers' stability in case of their high strength and bridging of the roof in the abandoned workings.

The oldest theories describing the distribution of stresses in the vicinity of a mining excavation were developed at the end of the 19th century. Fayol [2] published the results of research on the behaviour of resistance stock-piles supporting the roof. For the first time he used the term "arch" in relation to the load on the "pressure arch" floor layers.

In 1954 Ruppenejt developed a theory of bending strata [3]. He assumed that under the mining excavation, the roof layers are bended along the arc in the close proximity to the longwall face. In 1955, Sałustowicz [4] developed idea of Budryk on applying the Beam on Elastic Foundation theory to solve the problems of stress distribution in the rock masses near longwall face. The solution assumed that the direct roof of the coal stratum formed a bracket plate above it, which, supported along the longwall, was subject to cylindrical bending. If so, he applied the bending of straight beams theory. "According to the stress wave theory, we consider the roof rock layer as a beam lying on the elastic foundation on which the stratum is mined. The primary stress $p_{z}=\gamma \cdot h$ coming from overlaid beds acts on the beam. Under such conditions, the beam is bended; the bracket bends downwards, while the part of the beam lying above the stratum takes the shape of a wave-like line [...]. The flaking bracket, exerting additional load on the deck causes a stress increase in relation to the primary $p_{z}$ value; the increased stress is called exploitation pressure (stress). [...] The roof bending and the stress distribution in the coal stratum follow the wave-like line."[4]

Generally, if considering the issue of exploitation stress next to the longwall face, the mostknown theories are: the stress wave theory and the beam on an elastic foundation bend theory.

\section{Basic theories describing the distribution of stresses in the roof in the vicinity of longwall excavations}

\subsection{Stress wave theory}

The assumptions of this well-known theory were described by Budryk in 1933. In 1950, Sałustowicz supplemented it with a solution to the problem of backfilling excavation. Generally, in this solution, the roof of thickness $h$ is loaded with a uniformly distributed stress of the overburden rock layers $p_{z}$, and the coal stratum is treated as an elastic (Winkler's) substrate. The roof beam over the exploited space forms a bracket with length $l$.

After solving the differential equation of the bending of the beam line and making a series of assumptions, we obtain the equation of the roof bending line:

$$
w=\frac{p_{Z}}{c_{1}}+e^{-\beta \cdot x} \cdot \frac{p_{Z} \cdot l}{4 \cdot \beta^{2} \cdot E \cdot I}\left[\left(1+\frac{2}{\beta}\right) \cdot \cos \beta x-l \cdot \sin \beta x\right]
$$

where:

$w$ - subsidence of the roof,

$x$ - distance from the longwall face,

$p_{z}$ - vertical overburden rocks mass stress acting on the beam,

$l$ - length of the bracket over the exploited space, 
$\beta$ - constant, $\beta=\sqrt[4]{\frac{c_{1}}{4 \cdot E \cdot I}}$,

$c_{1}$ - coefficient of specific resistance of the coal stratum as elastic foundation,

$E$ - Young's modulus of the roof beam,

$I$ - moment of inertia of the roof.

The equation of stress distribution in the coal stratum under caving:

$$
\sigma_{z}=p_{z}+\beta^{2} \cdot p_{z} \cdot l \cdot e^{-\beta \cdot x} \cdot\left[\left(1+\frac{2}{\beta}\right) \cdot \cos \beta x-l \cdot \sin \beta x\right]
$$

The highest stresses equated with exploitation stress at the face (for $x=0$ ):

$$
\sigma_{\text {zmax }}=p_{z} \cdot(\beta l+1)^{2}
$$

Assuming

$$
\beta=\sqrt[4]{\frac{c_{1}}{4 \cdot E \cdot I}}
$$

We get

$$
\sigma_{z \max }=p_{z} \cdot\left(l \cdot \sqrt[4]{\frac{c_{1}}{4 \cdot E \cdot I}}+1\right)^{2}
$$

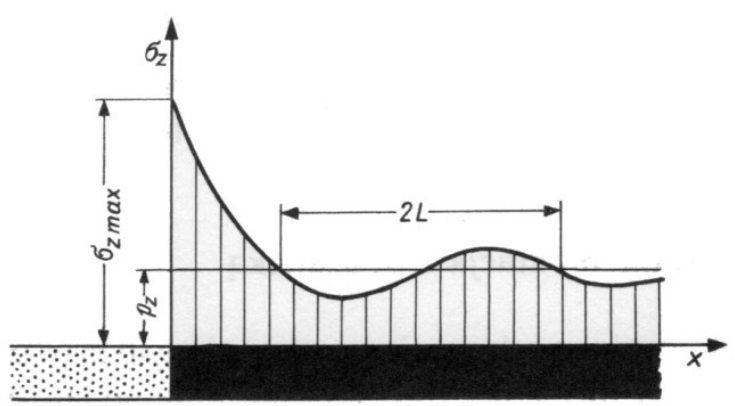

Fig. 1. Distribution of stresses in a coal stratum exploited with the roof layers caving for the wave stress theory. [1]

Stress wave length

$$
2 \cdot L=2 \cdot \pi \cdot \sqrt[4]{\frac{4 \cdot E \cdot I}{c_{1}}}
$$

Thus, exploitation stress

$$
\sigma_{z \max }=p_{z} \cdot\left(\frac{\pi \cdot l}{L}+1\right)^{2}
$$

Citing Kłeczek: "The value of exploitation stress in the longwall is directly proportional to the stress of the overburden rock layers, i.e. to the depth at which the excavation is carried out. Stress is greater if length of the roof rock bracket is greater. Stress depends on the strength of the roof rocks; with strong rocks, the roof beam is longer and therefore stress in the stratum is greater. The exploitation stress in the vicinity of longwall wall is greater, the 
wavelength is smaller, i.e. if the more rigid the stratum (coefficient $c_{1}$ ) in relation to the stiffness of the $E \cdot I$ of roof.

\subsection{Beam on Elastic Foundation (BEF) theory}

Let's start from the curvature of beam equation caused by the bending moment:

$$
\frac{d^{2} w}{d x^{2}}=-\frac{M_{g}}{E \cdot I}
$$

where:

$M_{g}$ - bending moment of the roof beam,

$E$ - modulus of elasticity of the roof beam, $E=\frac{E^{\prime}}{1-\vartheta^{2}}, E^{\prime}$ - elasticity coefficient of roof rocks, $I$ - inertia moment of the roof beam, $=\frac{h^{3} \cdot l}{12}, h$ - thickness of the roof beam.

After making allowance for the lateral force $T$, transformations, among others twice differentiation, summation, the characteristic equation of the roof bending line. The equation of the roof bending line and stress distribution in the strata are obtained:

$$
\sigma_{z}=p_{z}+\frac{E_{c_{1}}}{m} \cdot\left(A_{2} \cdot e^{r_{2} x}+A_{4} \cdot e^{r_{4} x}\right)
$$

where:

$A_{2}, A_{4}$ - constants of integration,

$E_{c l}$ - coefficient of coal elasticity,

$r_{2}, r_{4}$ - real roots of the equation of the characteristic roof bending line.

For the exploitation of the coal stratum with a large thickness and low elasticity coefficient and for a thin roof layer with a high elasticity coefficient, stress progression in the coal stratum is wave-like.

Length of wave:

$$
2 L=\frac{2 \cdot \pi}{\beta_{2}}=\frac{2 \cdot \pi}{\sqrt{\sqrt{\frac{3 \cdot E_{c_{1}}}{E \cdot m \cdot h^{3}}}-\frac{0.6 \cdot(1+\vartheta) \cdot E_{c_{1}}}{E \cdot m \cdot h}}}
$$

The maximum value of exploitation stress in the longwall face:

$$
\sigma_{z \max }=p_{z}\left\{1+l\left[2 \cdot \sqrt{\sqrt{\frac{3 \cdot E_{c_{1}}}{E \cdot m \cdot h^{3}}}-\frac{0.6 \cdot(1+\vartheta) \cdot E_{c_{1}}}{E \cdot m \cdot h}}+l\left(\sqrt{\frac{3 \cdot E_{c_{1}}}{E \cdot m \cdot h^{3}}}-\frac{1.2 \cdot(1+\vartheta) \cdot E_{c_{1}}}{E \cdot m \cdot h}\right)\right]\right\}
$$

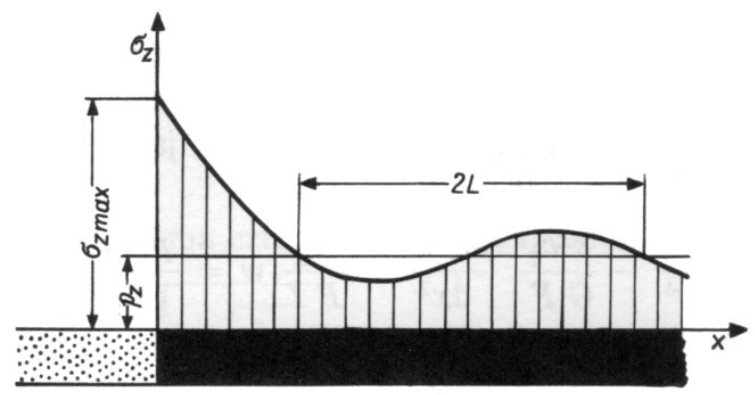

Fig. 2. Distribution of stresses in a coal stratum exploited with a caving based on the Beam on Elastic Foundation (BEF) theory. [1] 


\subsection{Values of exploitation stress for given mining geological conditions}

For geological and mining conditions such as those take for the numerical model (Chapter 3) calculations were made for solutions based on the Beam on Elastic Foundation (BEF) and stress wave theories.

Depth of exploited coal stratum: $H=697 \mathrm{~m}$.

Bulk density of the overburden: $\gamma=7 \mathrm{kN} / \mathrm{m}^{3}$.

Thickness of coal stratum: $m=3.0 \mathrm{~m}$.

Elasticity coefficient of the coal stratum: $E_{c l}=3000 \mathrm{MPa}$.

Thickness of the direct roof: $h=9.5 \mathrm{~m}$.

Elasticity coefficient of direct roof rocks: $E^{\prime}=18000 \mathrm{MPa}$.

Poisson's ratio of direct roof rocks: $v=0.3$.

$$
\begin{aligned}
& p_{z}=24.22 \mathrm{MPa} \\
& E=19780 \mathrm{MPa}
\end{aligned}
$$

Length of the roof bracket: $l=4.0 \mathrm{~m}$

For the Beam on Elastic Foundation (BEF) theory:

- exploitation stress in the longwall face: $\sigma_{z \max }=36 \mathrm{MPa}$.

For stress wave theory:

- exploitation stress in the longwall face: $\sigma_{z \max }=22 \mathrm{MPa}$.

\subsection{Real distribution of stresses in the longwall face}

The distribution of vertical stress in the coal stratum (Fig. 3, the right part of the graph, exploitation from the right to the left) and in front of the wall (left part of the graph) based on stress measurements was presented by Biliński [5]. This distribution was made for a single longwall mining at a depth of $250 \mathrm{~m}$. The value of the exploitation stress $\sigma_{z \max }$ was about $55 \mathrm{kG} / \mathrm{cm}^{2}(5.4 \mathrm{MPa})$ - the largest was at a distance of about $5 \mathrm{~m}$ from the longwall face and it was equal to the coal stratum support $S_{b}$.

Similar distribution of stresses in the vicinity of the longwall excavation was presented by Majcherczyk [6] (Figure 4) citing Borecki and Chudek [7]. "According to this theory [substrate reaction theory], a zone of maximum stresses exists in front of the longwall face. The more stronger coal strata, the maximum stress gets higher rates and the zone of stress moves over the longwall face."[6]

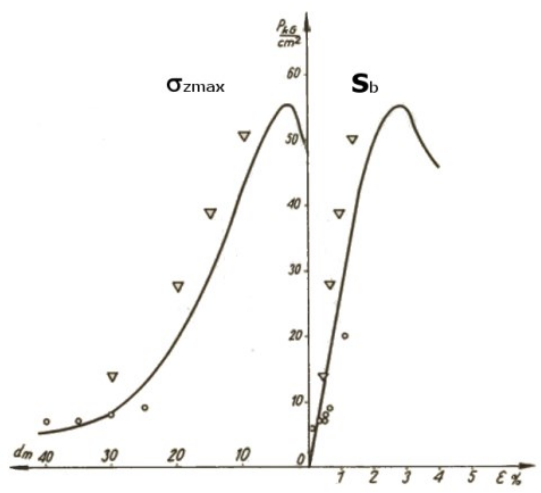

Fig. 3. Vertical stress in the coal stratum in front of the longwall face of $\sigma_{z \max }$ (left side of the graph) and load-support characteristics of the stratum $S_{b} ; d$ - distance from the longwall face, $\varepsilon$-vertical strains of the stratum (in the noexploited part) according to Biliński [5].

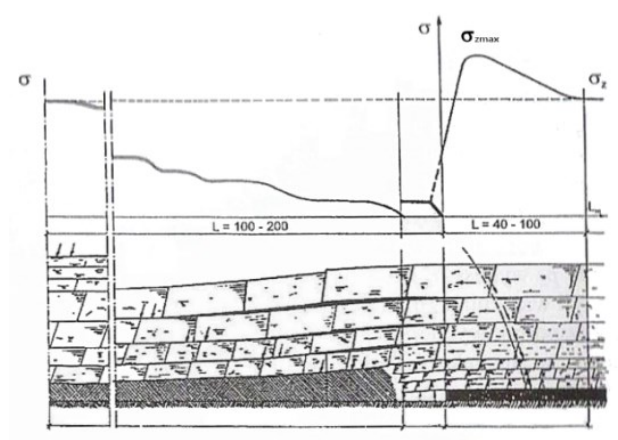

Fig. 4. Distribution of vertical stresses $\sigma_{z \max }$ in the coal stratum subjected to caving exploitation; $L$ - length of selected zones in $\mathrm{m}$ according to Majcherczyk [6]. 


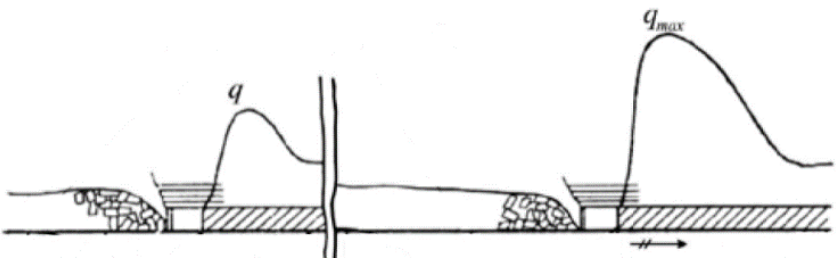

Fig. 5. Distribution of high stresses and unstressed zones along the longwall before exploitation (left side) and during exploitation (right side); $\quad q=\sigma_{z}$ according to Konopko [8].

Similar distribution of stresses was presented by Konopko [8]. Fig. 5 shows the hypothetical distribution of exploitation stress in front of the longwall face before and during exploitation. Assuming that the proportions in the figure have been kept, the maximum exploitation stress is $4 \div 8 \mathrm{~m}$ in front of the longwall face.

\section{Distinct Element Method (DEM) and the numerical model of longwall mining}

\subsection{Distinct Element Method (DEM)}

Rocks are usually discontinuous, heterogeneous, anisotropic and not (only) elastic. Describing materials with such complex properties using mathematical formulas is difficult, sometimes impossible. To solve many engineering problems, simplifications are applied and the rocks treated as continuous, homogeneous, isotropic and elastic. Such assumptions are in many cases sufficient. Detailed analysis and description of phenomena occurring in rocks and rock masses requires taking into account the real structure of rocks.

Generally, the rocks are made of mineral grains glued by a significantly lower strength binder. Rock material in the micro scale is often cracked and defected. On the macro scale there are local and regional discontinuities, e.g. faults.

These properties of rock material make the use of computational programs based on solutions of continuous medium mechanics limited. Of course, there are packages of programs based, e.g. on the Finite Element Method (FEM) or Finite Differences Method (FDM), which allow modelling of phenomena occurring in rocks and rock masses. Sometimes, it is necessary to consider the fact that rocks are discontinuous materials.

The basics of the Distinct Elements Method (DEM) were formulated by Cundall [9]. Initially, this method was used to solve the problems of rock mechanics and soil mechanics. The method assumptions are more detailed described by Cundall and Hart [10] and also in the manuals of codes based on the DEM method - UDEC, PCC, PFC3D and 3DEC.

In the general case, DEM assumes that the models are made of distinct deformable polygon particles. The interaction of particles is a dynamic process of the medium states, which changes under influence of changes in internal forces. Contact forces, displacements of distinct element particles or aggregates and their deformations depend on displacements of singular particles. Movement of walls, particles and mass forces cause displacements. Speed of these behaviour depends on physical properties of the DEM medium. Distinct elements can be rigid or deformable. The vertices of the distinct elements can be rounded to optimize detection of contacts as they move.

Already the UDEC program has been described, also by the Authors themselves. UDEC has already been used for solving problems in the field of geomechanics and geoengineering. Numerical simulation has been simulated, among others, for: simplified longwall mining [11], stability of rock mass in the vicinity of the underground hockey stadium in Gjovik in Norway [12] (Fig. 6) and the Nishida bridge in Japan [13], methane migration from rock 
masses [14], field explosion test [15], the basis for masonry UDEC and 3DEC application [16] etc.
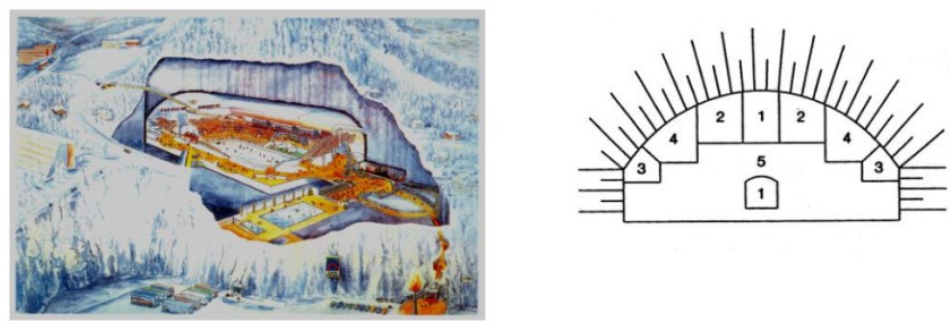

Fig. 6. Underground hockey stadium in Gjovik [12].

\subsection{Numerical model of the longwall caving mining}

The model was built using the UDEC v.4.0 program. The model's plate had dimensions of $1500 \mathrm{~m} \times 500 \mathrm{~m}(w \times h)$. Above the coal stratum, with a thickness of $h_{w}=3.0 \mathrm{~m}, 29$ rock layers with a thickness of $h_{s}=2.0 \div 20.0 \mathrm{~m}$, were modelled in the roof. Six layers of rock lay on the floor, with a thickness $h_{s p}=10.0 \mathrm{~m}$. The longwall mining was simulated by stages in the length from $L_{s}=25.0 \mathrm{~m}$ to $L_{s}=415.0 \mathrm{~m}$. All rocks layers had the characteristics of carboniferous rocks and the Coulomb-Mohr failure criterion was assigned (Table 1).

The lateral edges of the model could move along the vertical axis, and the points on the bottom edge could not move either along the vertical or horizontal axis. Floor of the coal stratum lay at a depth of $h_{z}=-697 \mathrm{~m}$. In order to simplify (reduce) the model, a vertical component $\sigma_{v}$ of $7.2 \mathrm{MPa}$ was applied to the upper edge of the model (Fig. 7a). Weakness planes - joints with a width (opening) of $d_{s}=0.0 \mathrm{~m}$ lay at an angle $\delta=95^{\circ}$ to rock layers and horizontally $\delta=0^{\circ}$ - separating individual layers. The distance between vertical joints $d_{v}$ was different: for the direct roof $5 \div 10 \mathrm{~m}$, for the main $10 \mathrm{~m}$, for the roof layers 15 and $20 \mathrm{~m}$ (Fig. $7 \mathrm{~b})$. The blocks (distinct elements) were deformable.

Table 1. Podstawowe własności skał i wiązań w modelu. Basic properties of rocks and bonds.

\begin{tabular}{|c|c|c|c|c|}
\hline No. & $\begin{array}{c}\text { Rock type / bonds / } \\
\text { support }\end{array}$ & \multicolumn{2}{|l|}{ Constant } & $\begin{array}{c}\text { Average } \\
\text { values }\end{array}$ \\
\hline & Sandstone (roof) & Bulk density & $\rho, \mathrm{kg} / \mathrm{m}^{3}$ & 2700 \\
\hline & & Bulk modulus & $K, \mathrm{MPa}$ & 5800 \\
\hline & & Shear modulus & $G, \mathrm{MPa}$ & 6300 \\
\hline \multirow{3}{*}{\multicolumn{2}{|c|}{ 2. Coal (stratum) }} & Bulk density & $\rho, \mathrm{kg} / \mathrm{m}^{3}$ & 1700 \\
\hline & & Bulk modulus & $K, \mathrm{MPa}$ & 1600 \\
\hline & & Shear modulus & $G, \mathrm{MPa}$ & 500 \\
\hline \multirow{3}{*}{\multicolumn{2}{|c|}{ 3. Sandstone (floor) }} & Bulk density & $\rho, \mathrm{kg} / \mathrm{m}^{3}$ & 2800 \\
\hline & & Bulk modulus & $K, \mathrm{MPa}$ & 6000 \\
\hline & & Shear modulus & $G, \mathrm{MPa}$ & 6500 \\
\hline \multirow{3}{*}{\multicolumn{2}{|c|}{ 4. Bonds of joints }} & Normal stiffness & $k_{n}, \mathrm{MPa}$ & $250 \div 1100$ \\
\hline & & Tangential stiffness & $k_{s}, \mathrm{MPa}$ & $100 \div 450$ \\
\hline & & Angle of friction & $\varphi,^{\circ}$ & $9 \div 17$ \\
\hline & $\begin{array}{l}\text { Hydraulic mechanized } \\
\text { support }\end{array}$ & Maximal support force & $p_{m}, \mathrm{MN}$ & 10 \\
\hline
\end{tabular}


The wall face was outcropped at $2.0 \mathrm{~m}$, for the next $4.0 \mathrm{~m}$ the roof was supported by elements simulating the hydraulic mechanized support and outcropped on the next $5.0 \mathrm{~m}$ in the caving (Fig. 7b).

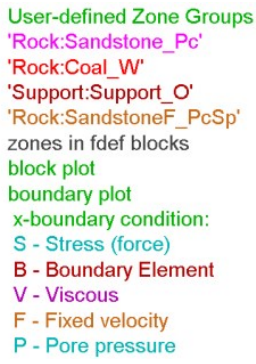

User-defined Zone Groups 'Rock:Sandstone_Pc'

'Rock:Coal W'

'Support:Support_O'

'Rock:SandstoneF_PcSp'

zones in fdef blocks

block plot

boundary plot

x-boundary condition:

S - Stress (force)

B - Boundary Element

$\mathrm{V}$ - Viscous

F - Fixed velocity

$\mathrm{P}$ - Pore pressure

LEGEND
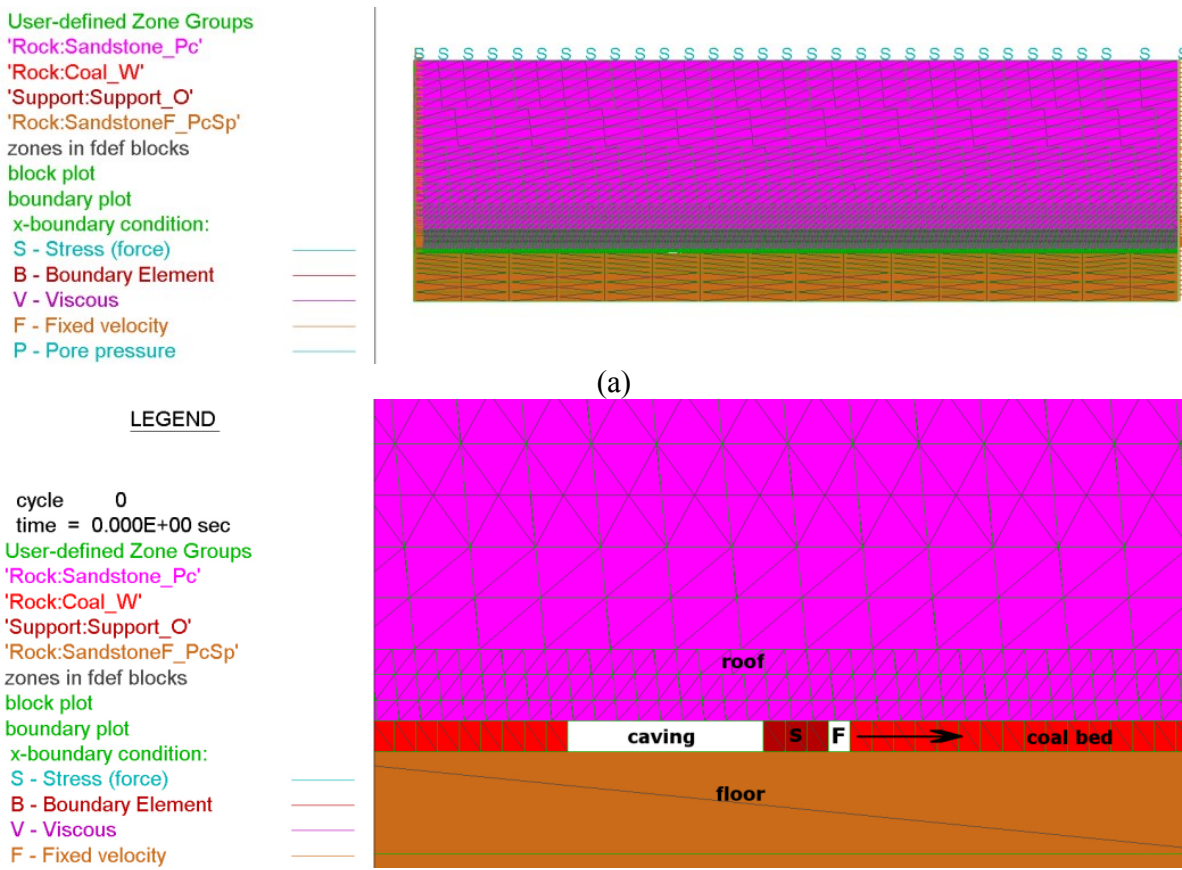

(a)

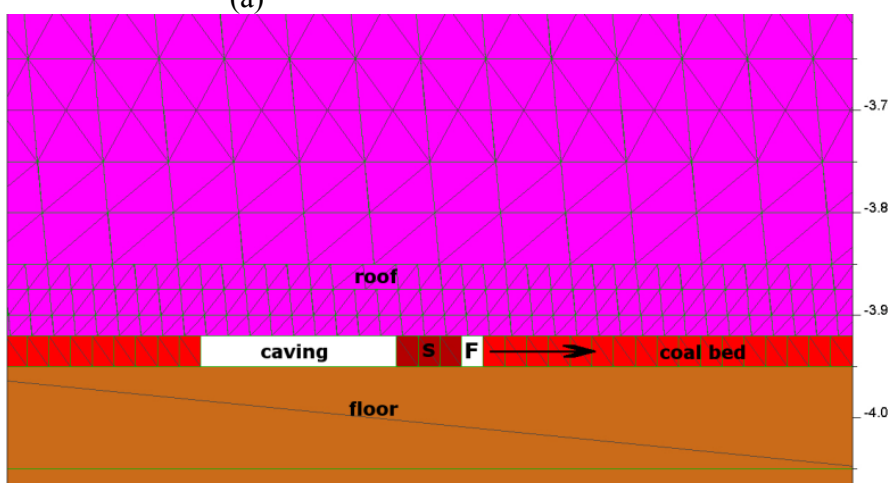

(b)

Fig. 7. Global (a) and local (b) view of the rock mass model in the vicinity of the longwall face.

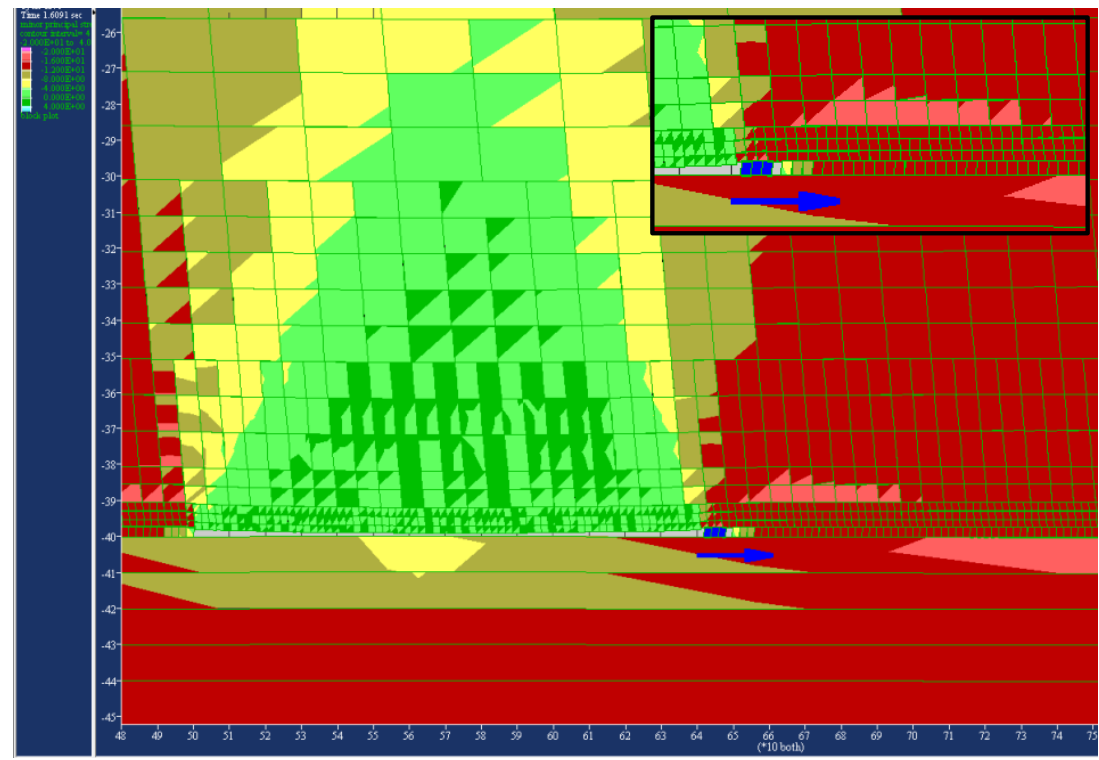

Fig. 9. Vertical stresses $\sigma_{z \max }$ in the rock mass and in the vicinity of the face after longwall advance equal to $150 \mathrm{~m}$. The zones of stresses concentrations $(>28 \mathrm{MPa})$ in front of the longwall face are marked as pink. 


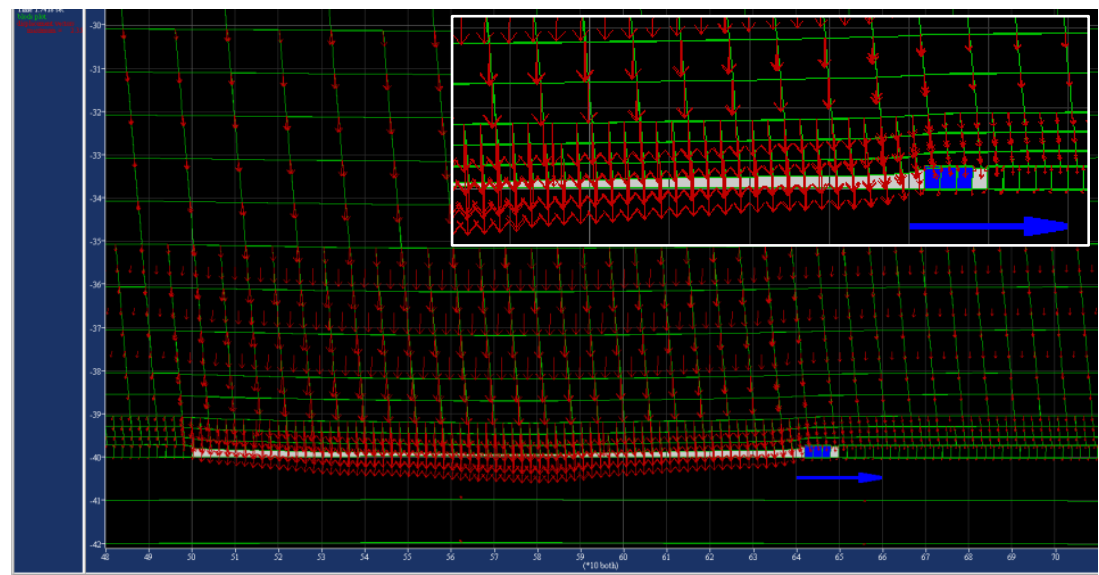

Fig. 10. Vectors of vertical displacement $d_{z}$ in the rock mass and in the vicinity of the face after longwall advance equal to $150 \mathrm{~m}$. The length of vectors is proportional to displacements. The maximum values of $d_{z}$ in the caving zone lead to $2.4 \mathrm{~m}$.

Selected results of the conducted numerical simulations for $150 \mathrm{~m}$ 's longwall advance are presented on Figures $9 \div 11$.

For virgin rock mass $\sigma_{z \max }$ obtains $16 \mathrm{MPa}$ (Fig. 9, red). A low tensile stress zone $\sigma_{z}<4 \mathrm{MPa}$ (dark green) and compressive stresses with values reaching up to $8 \mathrm{MPa}$ (light green and yellow) is over the caving zone. In front of the longwall face there is a concentration zone of compressive stresses (exploitation stress, pressure). Values of the compressive stresses reach up to $24 \mathrm{MPa}$ at a distance of about $10 \mathrm{~m}$ from the longwall face (pink). The largest vertical displacements of blocks $d_{z}$ occur in the caving zone (Fig. 10) and reach the value $2.4 \mathrm{~m}$. The vertical displacements progressively disappear over the caving zone. Also, in front of- and on the top of the longwall face it leads to small displacements $d_{z}$ up to a few $\mathrm{cm}$.

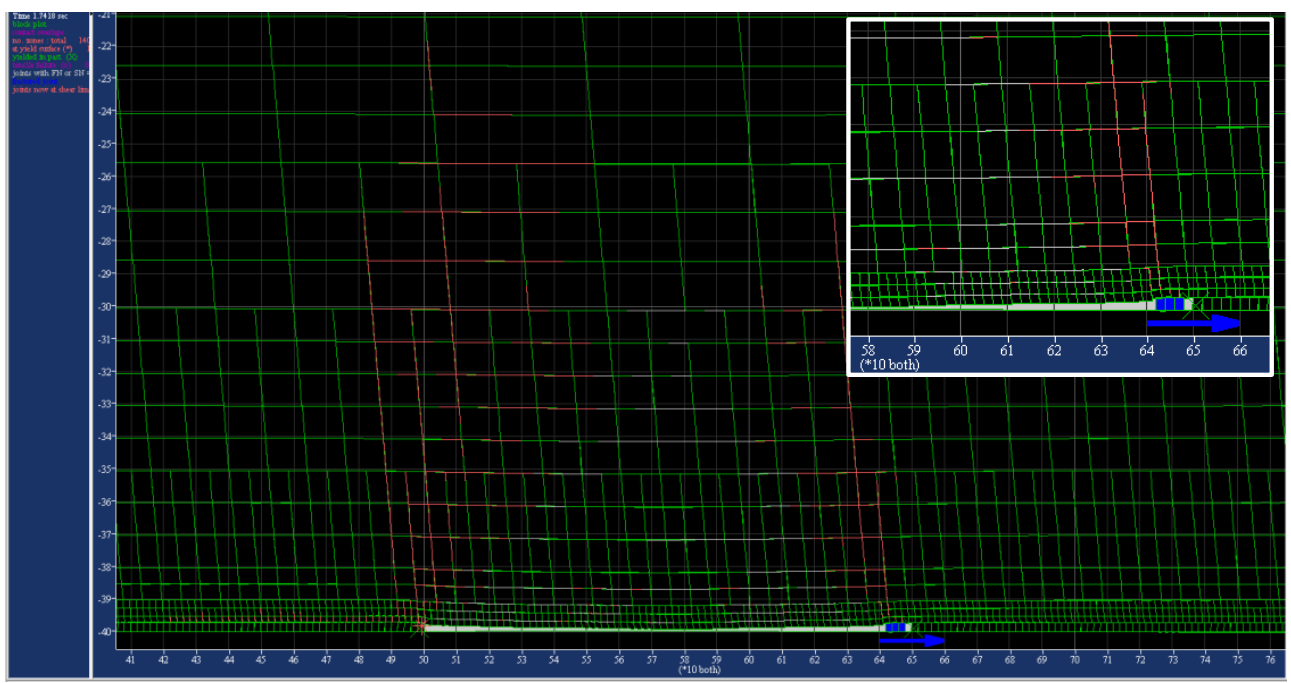

Fig. 11. Rock mass damage zones after the longwall advance is equal to $150 \mathrm{~m}$. Grey and red lines along the blocks edges indicate exciting of tensile and shear strength, contact absence between blocks and green $X$ sign - plasticity.

Fig. 11 shows the rock mass damage. Grey and red lines along the blocks edges indicate exciting of tensile and shear strength, contact absence between blocks and green $X$ sign plasticity. The damage (or fracture) zones of rock material are about $160 \mathrm{~m}$ above the 
completely exploited part of the coal stratum and the roof from the point where the exploitation started to the hydraulic mechanical support.

\section{Conclusions}

Knowing the distribution of stresses in the cases of underground mining excavations is difficult and complicated. In order to solve exploitation stress phenomena, the most wellknown theories: Beam on an Elastic Foundation (BEF) and the stress wave theories were applied. For the geological and mining conditions, for the coal stratum with a thickness of $3.0 \mathrm{~m}$ lying at a depth of $700 \mathrm{~m}$, the calculation of the exploitation stress $\sigma_{z \max }$ was carried out on the basis of Beam on an Elastic Foundation and the stress wave theories. Respectively, values of $\sigma_{z \max }$ equal to 36 and $22 \mathrm{MPa}$ were calculated.

Measurements of stresses in the vicinity of longwall excavation faces indicated that the zones of maximum exploitation stresses were displaced into the rock mass body before the longwall face of a few meters away.

To verify the exploitation stress problem, a 2D numerical rock mass model was built using the UDEC v. 4.0 code. The UDEC program was based on the Distinct Element Method (DEM). Models were made from distinct elements - blocks glued in places of contacts. The blocks might be deformable and the bonds between them might be broken or re-formed. DEM-based programs are specially designed for jointed and discontinuous materials. Due to complexity of calculations, especially in 3D (e.g. 3DEC), DEM-based programs are used rarely (in comparison to programs based on the finite element method; see [17]). The modelling experience of the UDEC program modelling is also relatively poor.

The built model's 2D plate had dimensions of $1500 \mathrm{~m} \times 500 \mathrm{~m}(w \times h)$. Above the coal stratum with a thickness of $h_{w}=3.0 \mathrm{~m}, 29$ rock layers were modelled in the roof, plus six layers were laid on the floor. The exploitation was simulated by stages from $L_{s}=25.0 \mathrm{~m}$ to $L_{s}=415.0 \mathrm{~m}$. All layers got characteristics of carboniferous rocks and the Coulomb-Mohr failure criterion. The joints were modelled - cracks of the width (opening) $d_{s}=0,0 \mathrm{~m}$ lying at angles $\delta=95^{\circ}$ and $\delta=0^{\circ}$ and separating the single rock layers.

Maps of distribution were obtained and they included: stresses, displacements and damage and fracture zones of rock mass. The obtained exploitation stress values $\sigma_{\max }=24 \mathrm{MPa}$ was similar to the obtained on the basis of analytical calculations. The maximum exploitation stress zone proceeded to a distance of about $10 \mathrm{~m}$ in front of longwall face, similarly to in situ stress measurements. Numerical modelling allowed to observe the range of rock mass damage zone and displacement of rock blocks. The calculations and analyses that were carried out (at this stage) allowed for positively verification of the possibility of using a program based on the Distinct Element Method for study the behaviour of the joined rock mass in the vicinity of the longwall face. They are a stage for further analyses and calibrations of new numerical models for various geological and mining conditions.

\section{References}

1. Z. Kłeczek Z., Geomechanika Górnicza Śląskie Wydawnictwo Techniczne, Katowice (1994)

2. M. Fayol, Sur Bul. de la Société de l'industrie minérale, II série, Tome 14, p. 818, (1885)

3. K. V. Ruppenejt, K.V.: Nekotoryje voprosy mechaniky gornych porod Ugletechnizdat, Moskwa (1954)

4. A. Sałustowicz, Mechanika górotworu. Cz. 1. Mechanika górotworu. Górnictwo t. III, Wydawnictwo Górniczo-Hutnicze, Katowice (1955) 
5. A. Biliński, Przejawy ciśnienia górotworu w polach eksploatacji ścianowej w pokładach węgla, ZN nr 221, s. Górnictwo z. 31, Politechnika Śląska, Gliwice (1968)

6. T. Majcherczyk, A. Szaszenko, E. Sdwiżkowa E., Podstawy geomechaniki. UWND AGH, Kraków (2006)

7. M. Borecki, M. Chudek, Mechanika górotworu, Skrypt Uczelniany nr 208, Politechnika Śląska. Gliwice (1968)

8. W. Konopko, Przegląd Górniczy, Miesięcznik Stowarzyszenia Inżynierów i Techników

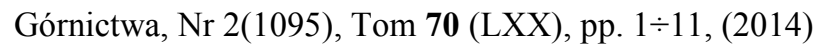

9. P. A. Cundall, Symp. ISRM Proc., Vol. 2, pp. 129 $\div 136$, Nancy (1971)

10. P. A. Cundall, R. D. Hart R.D., Numerical modelling of discontinua, Engineering Computations. Publisher MCB UP Ltd, 9 (2), pp. 101 $\div 113$, (1992)

11. M. Kwaśniewski, K. Tomiczek, Uproszczona symulacja eksploatacji pokładu z zawałem warstw stropowych za pomoca programu UDEC (v. 1.83, edukacyjna), Mechanika górotworu - zajęcia projektowe, KGBPiZOP, WGiG, Gliwice (1998)

12. N. Barton, L. Tunbridge, L. Løset, H. Westerdahl, L. Kristiansen, G. Vik, P. Chryssanthakis, Norwegian Olympic ice hockey cavern of $60 \mathrm{~m}$ span, Proc. of 7th ISRM Congress, Aachen (1991)

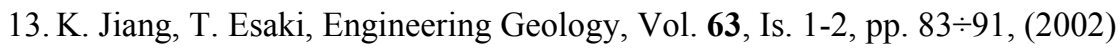

14. M. Kwaśniewski, S. Lasek, Journal of Coal Science and Engineering (China), Vol. 15, Is. 2, pp. $113 \div 119(2009)$

15. S. G. Chen, J. Zhao, Y.X. Zhou, UDEC modeling of a field explosion test, pp. 149 $\div 163$, Published online Aug 2010

16. J. V. Lemos, European Journal of Environmental and Civil Engineering, 12(7-8), pp. 915949, (2008)

17. K. Tomiczek, A note on the application of the distinct element method (DEM) to geomechanics, In monograph: Resources and resource-saving technologies in mineral mining and processing, Petrosani: Universitas Publishing, pp. 128 $\div 149$, Romania (2018) 